\title{
The Association of Body Mass Index and Ki67 Values in Patients with Endometrial Carcinoma
}

\author{
ALEXANDRU FURAU1\#, MARIUS LUCIAN CRAINA", CRISTIAN FURAU ${ }^{3}$, TUDOR CONSTANTIN LUCA ${ }^{4 \#,}$ \\ BOGDAN CORNELIU ANDOR ${ }^{5 *}$, DANIELA RADU6*, LAVINIA CRISTINA MOLERIU7*, DIANA CAMELIA BONTE ${ }^{8 *,}$ \\ DANIELA OANA TOADER ${ }^{9 *}$, GHEORGHE FURAU ${ }^{3}$ \\ 'Vasile Goldis Western University of Arad, Romania \\ UUniversity of Medicine and Pharmacy Victor Babes Timisoara, Department XII, Discipline of Obstetrics and Gynecology, \\ Timisoara, Romania \\ ${ }^{3}$ Vasile Goldis Western University OF Arad, Department of Obstetrics and Gynecalogy, Romania \\ ${ }^{4}$ University of Medicine and Pharmacy Victor Babes Timisoara, Department of Cardiology, Timisoara, Romania \\ ${ }^{5}$ University of Medicine and Pharmacy Victor Babes Timisoara, Department XV of Orthopedics, Traumatology, Urology and \\ Medical Imaging, Timisoara, Romania \\ University of Medicine and Pharmacy Victor Babes Timisoara, Department Surgery, Timisoara, Romania \\ UUniversity of Medicine and Pharmacy Victor Babes Timisoara, Department of Functional Sciences, Medical Informatics and \\ Biostatistics Discipline, Timisoara, Romania \\ ¿University of Medicine and Pharmacy Victor Babes Timisoara, Department II, Discipline of Biochemistry and Pharmacology, \\ Timisoara, Romania \\ ${ }^{9}$ National Institute for Mother and Child Health, Alessandrescu-Rusescu, Polizu Clinical Hospital, Bucharest, Romania
}

\begin{abstract}
Endometrial cancer begins in the layer of cells that form the lining (endometrium) of the uterus. Endometrial cancer is often detected at an early stage because it frequently produces abnormal vaginal bleeding, which prompts women to see their doctors. If endometrial cancer is discovered early, removing the uterus surgically often cures endometrial cancer. The study included all patients who had been evaluated for vaginal bleeding in Obstetrics and Gynecology Department of Clinical Emergency County Hospital, Timisoara between 20162018. Of the 195 cases of uterus scraping, 19 cases were labelled as malignant endometrial pathology. For the statistical analysis we calculated some descriptive statistics for the age parameter and the BMI (body mass index) parameter in our disease sample and we compared the BMI values to the BMI values from the control sample As well, we tested to see if there is an association between the Ki-67 values and the HER-2 I neu status in patients with or without endometrial carcinoma. In order to test the significance we applied a Mann -Whitney test, for $\alpha=0.05$ set as a confidence level. Unfortunately, in the case of our study group, type 1 endometrial cancers are found in only 5 cases, unlike other countries where most of endometrial cancers are diagnosed early (80\% in the first stage) and the 5-year survival rate is about $95 \%$. In any case, the 5 -year survival rate is much lower if there is involvement of regional lymph nodes or distant metastasis (68\% and 17\%, respectively) - as in our case where all cases were classified as Stage III and IV. By running the statistical test we obtained extremely significant differences in the BMI of our patients $(p<0.001)$, the diseased patients tend to have higher BMI values. As well, when we tested the possible association between the Ki-67 values and the HER-2 / neu status in our two groups (patients with or without endometrial carcinoma) we obtained extremely significant differences $(p<0.001)$. The Ki-67 values are increasing proportionally with the carcinoma staging. An endometrial biopsy is the most commonly used test for endometrial cancer and is very accurate in postmenopausal women.
\end{abstract}

Key words: endometrial carcinoma, HER-2 / neu, Ki-67, immunohistochemistry

Endometrial cancer is the result of abnormal cell growth originating from the endometrium and have the ability to invade or spread to other locations[1]. The first symptom is vaginal bleeding, between periods, or in postmenopausal patients. Other symptoms include dysuria, pain during intercourse or pelvic pain. Endometrial cancer is commonly diagnosed with endometrial biopsy or biopsy curettage.

If in some developed countries (US, UK etc.) endometrial carcinoma occupies the first place as a frequency among gynecological malignancies [2-5].

According to the studies, the age at which it is found in more than $90 \%$ of cases is over 50 years old, but can also occur in women under 40 years old. If in the United States, over $80 \%$ of cases are diagnosed in stage 1, unfortunately in our country there are a number of risk factors incriminated in the occurrence of the disease. Approximately $40 \%$ of cases are related to obesity, diabetes, hypertension, an ovulatory infertility, nulliparity, infertility, polycystic ovary syndrome early menarche and late menopause, family history, BRCA gene mutations, a long exposure to estrogen, tumors secreting estrogen, tamoxifen treatment [6-9].

There have also been identified a number of protective factors against endometrial carcinoma: the use of combined oral contraceptives, the use of menopausal hormone replacement therapy.

In patients diagnosed with endometrial carcinoma, there was no consensus on levels and correlation with clinical pathologic factors and predictive value of HER-2 / neu alterations. 
Endometrial carcinoma can be classified into two distinct groups:

Type 1 endometrial cancers may arise from complex atypical hyperplasia and is pathogenetically linked to unopposed estrogenic stimulation. Approximately $80 \%$ of the endometrial carcinomas are type 1, i.e. low histological tumor type and grade $(\mathrm{G} 1, \mathrm{G} 2)$. These cancers can occur in the event of persistent unopposed estrogen stimulation and tend to occur in perimenopausal women. They are generally preceded by endometrial hyperplasia and are estrogen receptor (ER) and/or progesterone receptor (PR) positive. Molecular changes associated with type 1 endometrial cancers include mutations by deletion / inactivation of the PTEN tumor suppressor gene (36-83\%), microsatellite instability (20-40\%), KRAS mutations (15$30 \%$ ) and gain-of-function $\beta$-catenin mutation (25-40\%) [10-12].

Type 2 endometrial cancers develop from atrophic endometrium and is not linked to hormonally driven pathogenesis. By contrast, type II endometrial cancers are histologically non-endometrioid cancers and have no association with the increased levels of endogenous or exogenous estrogen. They tend to appear in older women being very aggressive, with a tendency to lymph-vascular invasion, distant dissemination, and deep tissue invasion. They represent almost half of the mortality rates due to endometrial cancer. Genetic changes associated with Type Il endometrial cancers include aneuploidy, p53 mutations (80-90\%), p16 inactivation (40\%), human epidermal growth factor receptor 2 overexpression (HER-2/ Neu (40$80 \%$ ) and changes in E-cadherin expression (80-90\%).

Deregulation of the mechanisms controlling cell proliferation and apoptosis is known in the case of malignant neoplasms. Recent data on Ki-67 and HER-2 / neu that are involved in these processes merged as valuable prognostic tools [13].

HER-2/neu protooncogene is associated with an unsatisfactory prognosis in in human breast and ovarian cancer. The significance of HER-2/neu in endometrial carcinoma is less clearly established. Some authors analyzed HER-2/ neu gene amplification by fluorescence in situ hybridization and protein overexpression measured by immunohistochemistry [14-16].

\section{Experimental part}

Material and methods

We studied HER-2/neu amplification status and Ki-67 expression in hysterectomy specimens of endometrial carcinoma, determined by immunohistochemical analysis correlated with some clinical and pathological factors. The histological grade and stage of endometrial cancers were assigned according to the FIGO criteria. HER-2/neu signals were scored on histological sections in at least 150 neoplastic cells using a conventional microscope (Zeiss).

It is well known that increased cell proliferation is responsible for tumor growth. Among the markers of proliferation, our study suggested that Ki-67 provided additional information on clinical progression and prognosis.

The study included all patients who had been evaluated for vaginal bleeding in Obstetrics and Gynecology Department of Clinical Emergency County Hospital, Timisoara between 2016-2018. Before performing curettage biopsy, the thickness of the endometrium was measured with transvaginal ultrasonography. Of the 195 cases of uterus scraping, 19 cases were labeled as malignant endometrial pathology. After surgery, the anatomopathological results consisted of 13 cases of endometrial adenocarcinoma, 3 cases of mixed carcinoma and 3 cases of clear-cell carcinoma. Age of patients ranged between $54-82$ years, with a higher frequency between 60-67 years ( 13 cases) [17-19].

The statistical analysis was performed using two different programs: Microsoft Excel and SPSSv17. For the descriptive statistics we calculated the central tendency parameters and the dispersion parameters, we made frequency tables and we plotted the most important results. For the statistical significance we performed a Mann - Whitney test, having $\alpha=0.05$ as the confidence level.

\section{Results and discussions}

It is important that malignantendometrial pathology can be detected early and the lesions are limited to the uterus in $70 \%$ of the cases. Unfortunately, in the case of our study group, type 1 endometrial cancers are found in only 5 cases, unlike other countries where most of endometrial cancers are diagnosed early ( $80 \%$ in the first stage) and the 5-year survival rate is about $95 \%$. In any case, the 5 -year survival rate is much lower if there is involvement of regional lymph nodes or distant metastasis ( $68 \%$ and $17 \%$, respectively) as in our case where all cases were classified as Stage III and IV $[20,21]$.

A common risk factor encountered in 15 cases was obesity that increases the risk of developing endometrial cancer; data suggests that a 2- to 3-fold greater than in people of normal weight (about $16 \mathrm{~kg}$ ) increases the risk of developing endometrial cancer. Obesity is known to increase endogenous estrogen, because the presence of fat appears to be responsible for the conversion of androstenedione to estrogens in case of higher rates of overweight.

Upon all our diseased patients $(\mathrm{N}=19)$ we calculated the central tendency and dispersion parameters for the age and BMI (body mass index) parameters (Table 1) and as well for the nominal variables we calculated frequency tables (Table 2). As well we plotted the most important results by using histograms (Figure 1), and a column and a pie chart (Figure 2).

After observing the characteristics of our data we tested to see if an increased BMI can influence the appearance of endometrial carcinoma. For this we applied a MannWhitney test and we obtained extremely significant differences between this two mean BMI values. The diseased patients are having a higher BMI value.

Table 1

THE CENTRAL TENDENCY AND DISPERSION PARAMETERS FOR THE AGE AND BMI (BODY MASS INDEX) PARAMETERS.

\begin{tabular}{|l|r|r|}
\hline Statistics & \multicolumn{1}{|l|}{ Age } & \multicolumn{1}{l|}{ BMI } \\
\hline Mean & 62.78 & 29.44 \\
\hline Standard Error & 1.41 & 0.72 \\
\hline Median & 62.5 & 29 \\
\hline Mode & 61 & 29 \\
\hline Standard Deviation & 6.00 & 3.07 \\
\hline Sample Variance & 35.95 & 9.44 \\
\hline Kurtosis & 5.99 & 0.49 \\
\hline Skewness & 1.78 & -0.60 \\
\hline Range & 28 & 12 \\
\hline Minimum & 54 & 22 \\
\hline Maximum & 82 & 34 \\
\hline Sum & 1130 & 530 \\
\hline Count & 18 & 18 \\
\hline
\end{tabular}




\begin{tabular}{|c|l|r|r|}
\hline \multirow{4}{*}{$\begin{array}{c}\text { Carcinoma } \\
\text { distribution }\end{array}$} & Pathology & No & Percentage \\
\cline { 2 - 4 } & Mixed carcinoma & 13 & $68.42 \%$ \\
\cline { 2 - 4 } & Clear cell carcinoma & 3 & $15.79 \%$ \\
\cline { 2 - 4 } & Total & 3 & $15.79 \%$ \\
\hline \multirow{4}{*}{ Uterine scraping } & Malign endometrium cells & 19 & $\mathbf{1 0 0 . 0 0} \%$ \\
\cline { 2 - 4 } & Benign endometrium cells & 176 & $9.74 \%$ \\
\cline { 2 - 4 } & Total & $\mathbf{1 9 5}$ & $\mathbf{1 0 0 . 0 0} \%$ \\
\hline
\end{tabular}

Histogram of age distribution

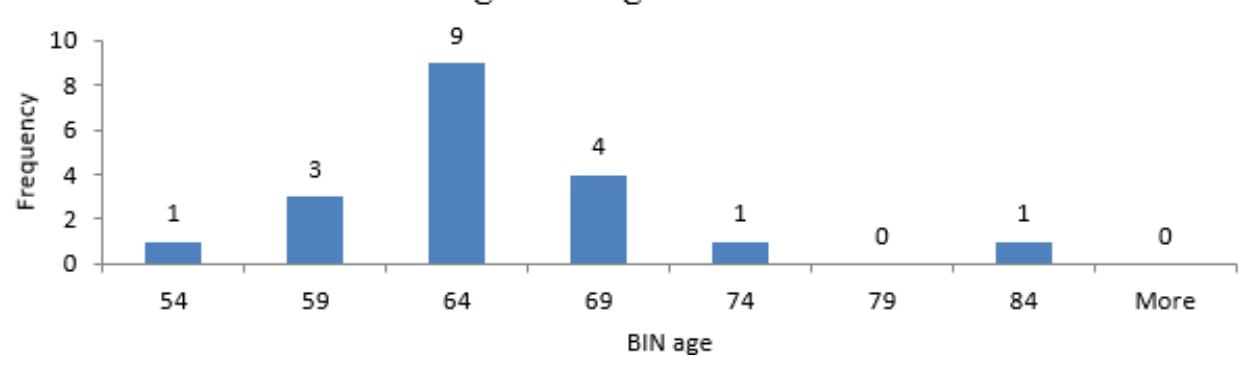

significance of $\mathrm{Ki}-67$ in predicting endometrial carcinoma are variable.

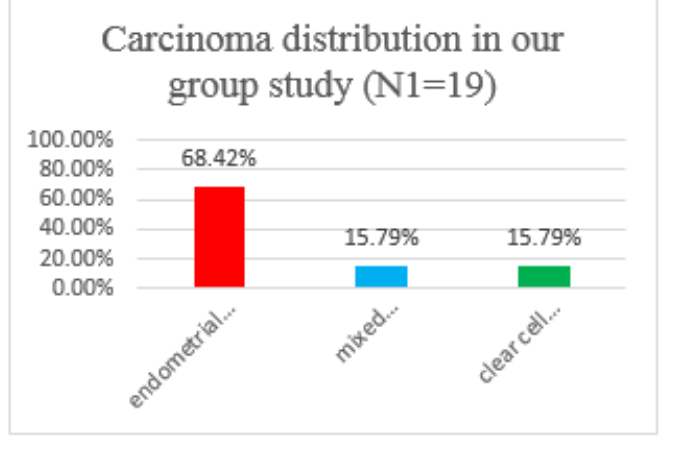

\section{Distribution of endometrial cells}

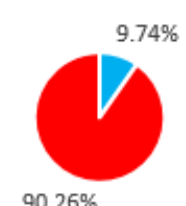

$90.26 \%$

- Malign end ometrium cells

- Benign endometrium cells

Fig. 2. We present the distribution of the carcinoma in our diseased group (N1=19) and the endometrial cell distribution in the entire group ( $N=195)$

In the end of our study we tested the possible association between the Ki-67 values and the HER-2 / neu status in our two groups (patients with or without endometrial carcinoma) and we obtained extremely significant differences between the groups $(p<0.001)$.

So we can say that Ki-67 values are increasing proportionally with the carcinoma staging.

\section{Conclusions}

According to published studies, we noticed that Ki-67 reactivity in 2/3 of our cases, increased along with the grade and stage of tumours and the myometrium invasion progressed along with the presence of lymph vascular space invasion. These findings indicate a severe deregulation of the cell cycle in cases with more aggressive oncogenic behaviour. However, data prognostic
Table 2

WE PRESENT THE FREQUENCY TABLE FOR THE NOMINAL VARIABLES FROM OUR STUDY. IN THE FIRST PART WE HAVE ONLY THE PATIENTS WITH CARCINOMA AND IN THE SECOND PART WE HAVE ALL THE PATIENTS WHO SUFFERED AN UTERINE SCARPING BETWEEN 2016 - 2018 IN OUR CLINIC.

Fig. 1.We present the age distribution of our patients

\section{References}

1.***National Cancer Institute. 22 April 2014. Archived from the original on 3 September 2014.

2.***WHO. GLOBOCAN 2012: Estimated cancer incidence, mortality and prevalence worldwide in 2012. 2012; http://globocan.iarc.fr/Pages/ fact sheets_population.aspx .

3.LEE NK, CHEUNG MK, SHIN JY, et al. Prognostic factors for uterine cancer in reproductive-aged women. Obstet Gynecol. 109: 655- 662, 2007.

4. ${ }^{* * *}$ Center for Sanitary Statistics and Medical Documentation National Cancer Registry, MSP, Bucharest 2016.

5.***American Cancer Society. Cancer Facts \& Figures. Atlanta, GA: American Cancer Society;2015 in Romania it occupies the 4th place among gynecological malignancies, accounting for $7.8 \%$ of them. Center for Sanitary Statistics and Medical Documentation National Cancer Registry, MSP, Bucharest 2016.

6.SCHMANDT R.E., et al. Understanding obesity and endometrial cancer risk: opportunities for prevention. Am J Obstet Gynecol,. 205(6):518-25, 2011.

7.HOFFMAN BL, SCHORGE JO, SCHAFFER JI, HALVORSON LM, BRADSHAW KD, CUNNINGHAM FG, eds. Endometrial Cancer. Williams Gynecology (2nd ed.). McGraw-Hill. p. 818. ISBN 978-0-07-171672-7, 2012.

8.SHUTTER J, WRIGHT TC Jr. Prevalence of underlying adenocarcinoma in women with atypical endometrial hyperplasia. IntJ Gynecol Pathol. 24(4):313-8, 2005.

9.HAHN HS, et al. Concurrent endometrial carcinoma following hysterectomy for atypical endometrial hyperplasia. Eur J Obstet Gynecol Reprod Biol., 150(1):80-3, 2010.

10.GADDUCCI A, COSIO S, SPIRITO N et-al. Clear cell carcinoma of the endometrium: a biological and clinical enigma. Anticancer Res., 30 (4): 1327-34, 2010.

11.SMITH-BINDMAN R, WEISS E, FELDSTEIN V. How thick is too thick? When endometrial thickness should prompt biopsy in postmenopausal women without vaginal bleeding. Ultrasound Obstet Gynecol, 24 (5): 558-65, 2004.

12.NOGAMI Y, IIDA M, BANNO K et-al. Application of FDG-PET in cervical cancer and endometrial cancer: utility and future prospects. Anticancer Res., 34 (2): 585-92, 2014.

13.GUPTA A, DESAI A, BHATT S. Imaging of the Endometrium: Physiologic Changes and Diseases: Women's Imaging. Radiographics : a review publication of the Radiological Society of North America, Inc. 37 (7): 2206-2207, 2017. 
14.MURESAN A., LAZAR E., DEMA A., SARGAN I. et al. The antigen Ki67: marker of the tumoral proliferation in the invasive mammary cancer and the connection with the classical prognostic factors, Virchows Archiv Volume: 457 Issue: 2 Pages: 168-168, 2010.

15.MURESAN A. M., LAZAR E., RAICA M., SARGAN I. et al., HER2 immunoexpression in invasive breast cancer: morpho-clinic and prognostic correlations, Virchows Archiv Volume: 455 Pages: 193 - 193 Published: Aug 2010.

16.MURESAN A. M., LAZAR E., RAICA M., SARGAN I. et al., The study of an immunohistochemical aggressivity marker in mammary carcinomas, Virchows Archiv Volume: 455 Pages: 194 - 194 Published: Aug 2010.

17.PANTEA S., CRAINA M., CHIRIAC V.D., MOLERIU R.D., BOGLUT A., BACEAN MILOICOV O.C., PETRE I., Anatomopathological and Histopathological Aspects of Malignant Tumors of the Uterus, The 13th Conference of the Romanian-German Society of Obstetrics and Gynecology,Timisoara, Romania, 14-16September 2017, pag 147 - 150, Ed. Filodiritto Editore Proceeding, ISBN 978-88-95922-959, 2017.

18.FURAU C., FURAU Gh, TATARU A.L., CRAINA M, PANTEA S., ILYES S.G., BOGLUT A., MOLERIU L.C., PETRE I., Pathology of Postmenopause in Women's Range Arad County, The 13th Conference of the Romanian-German Society of Obstetrics and Gynecology,Timisoara, Romania, 14-16 Sept. 2017, pag 177 - 183, Ed. Filodiritto Editore Proceeding, ISBN 978-88-95922-95-9, 2017.
19.PANTEA S., DUTA C., SARGAN I., LAZAR F. PAPURICA F M., BALASAGURAGATA C., BORDOS D., Histerectomia totala vaginala asistata laparoscopic cu evidare ganglionara pentru cancer de col incipient tehnica operatorie. Chirurgia, 106: 365-368, Nr. 3, Mai - Iunie, ISSN 1221-9118, ISSN on line 184, 2011.

20.BALASAN C., CRAINA M., PETRE I., MOLERIU R.D., POP E., PANTEA S., STOIAN D. - New Concepts on HPV Risk Factors Associated with Premalignant Lesions of Cervical Cancer, The 4 th Congress of the Romanian Society for Minimal Invasive Surgery in Gynecology, Annual Days of the National Institute for Mother and Child Health Alessandrescu-Rusescu, 1-3 November, 2018, Bucharest, Romania, pag 119-123, Ed. Filodiritto Editore Proceedings, ISBN 978-88-8581348-9, 2019.

21.FURAU A., FURAU C., CRAINA M., IACOB R., POP E., BOLINTINEANU S.L., MOLERIU L.C., STOIAN D., PETRE I.,Transvaginal Ultrasonography for Identifying Endometrial Pathology, The 4 th Congress of the Romanian Society for Minimal Invasive Surgery in Gynecology, Annual Days of the National Institute for Mother and Child Health Alessandrescu-Rusescu, 1-3 November, 2018, Bucharest, Romania, pag 263-268, Ed. Filodiritto Editore Proceedings, ISBN 978-88-8581348-9, 2019.

Manuscript received 14.06.2019 